\title{
Thyroid Function in Pregnancy and Its Influences on Maternal and Fetal Outcomes
}

\author{
Forough Saki ${ }^{1}$; Mohammad Hossein Dabbaghmanesh ${ }^{1, *}$; Seyede Zahra Ghaemi ${ }^{2}$; Sedighe \\ Forouhari $^{3}$; Gholamhossein Ranjbar Omrani ${ }^{1}$; Marzieh Bakhshayeshkaram ${ }^{1, *}$ \\ ${ }^{1}$ Shiraz Endocrinology and Metabolism Research Center, Shiraz University of Medical Sciences, Shiraz, IR Iran \\ ${ }_{3}^{2}$ Department of Midwifery, Islamic Azad University, Estahban Branch, Estahban, IR Iran \\ ${ }^{3}$ Shiraz Infertility Research Center, Shiraz University of Medical Sciences, Shiraz, IR Iran \\ ${ }^{*}$ Corresponding authors: Marzieh Bakhshayeshkaram, Shiraz Endocrinology and Metabolism Research Center, Shiraz University of Medical Sciences, Shiraz, IR Iran, Tel: +98- \\ 7116473096, Fax:+98-7116473096, E-mail: nahendo2@sums.ac.ir; Mohammad Hossein Dabbaghmanesh, Endocrinology and Metabolism Research Center, Nemazee Hospital, Shiraz, \\ IR Iran. Tel:+98-7116473096, Fax:+98-7116473096, E-mail: dabbaghm@sums.ac.ir
}

Received: April 13, 2014; Revised: July 13, 2014; Accepted: August 3, 2014

\begin{abstract}
Background: Maternal thyroid function alters during pregnancy. Inadequate adaptation to these changes results in thyroid dysfunction and pregnancy complications.

Objectives: This prospective study aimed to evaluate the prevalence of thyroid diseases in pregnancy and its outcomes in south of Iran. Materials and Methods: This prospective study was conducted on 600 healthy singleton pregnant women who aged 18 to 35 years old at 15 to 28 weeks of gestation. We investigated the prevalence of thyroid dysfunctions in women. Multivariate analysis was performed to determine the effect thyroid dysfunction on obstetric and neonatal outcome.

Results: Thyroid stimulating hormone (TSH) levels of $0.51,1.18,1.68,2.4$, and $4.9 \mathrm{mIU} / \mathrm{L}$ were at 2.5th, 25th, 50th, 75th, and 97.5th percentile in our population. The prevalence of clinical hypothyroidism, subclinical hypothyroidism, overt hyperthyroidism, and subclinical hyperthyroidism in all pregnant women was $2.4 \%, 11.3 \%, 1.2 \%$, and $0.3 \%$, respectively. In addition, $1.4 \%$ of patients had isolated hypothyroxinemia.Clinical hypothyroidism was associated with increased risk of preterm delivery $(\mathrm{P}=0.045)$. Subclinical hypothyroidism had a significant association with intrauterine growth restriction (IUGR) $(\mathrm{P}=0.028)$ as well as low Apgar score at first minute $(\mathrm{P}=0.022)$. Maternal hyperthyroidism was associated with IUGR $(\mathrm{P}=0.048)$.

Conclusions: We revealed that thyroid dysfunction during pregnancy was associated with IUGR and low Apgar score even in subclinical forms. Further studies are required to determine whether early diagnosis and treatment of thyroid diseases, even in subclinical form, can prevent their adverse effect on fetus.
\end{abstract}

Keywords:UGR; Fetal Growth Retardation; Thyroid Dysfunction; Thyroid Disease

\section{Background}

Maternal thyroid function changes during pregnancy and inadequate adaptation to these changes results in thyroid dysfunction $(1,2)$. Some of these alterations in thyroid function occur due to increased thyroid hormone-binding globulin (TBG) concentration, increased iodine clearance in the kidneys, and thyrotrophic effect of human chorionic gonadotropin (HCG) $(3,4)$. In previous studies, the prevalence of overt hypothyroidism was $1 \%$ to $1.5 \%$, (1-9) and prevalence of subclinical hypothyroidism was $5 \%$ to $8 \%(8,10)$. The main pregnancy complications of hypothyroidism were anemia, preeclampsia, prematurity, low-birth weight (LBW), fetal distress in labor, fetal death, and congenital hypothyroidism, and neurocognitive deficits in children. Subclinical hypothyroidism might be associated with preterm delivery and low Apgar score $(1-3,11,12)$. Overt hyperthyroidism and subclinical hyperthyroidism affects about $0.2 \%$ to $0.8 \%$ and $0.4 \%$ to $1 \%$ of pregnancies, respectively $(1-3,13)$.
Maternal hyperthyroidism may cause preterm delivery, intrauterine growth restriction (IUGR), and neonatal thyrotoxicosis $(1-3,14)$. According to the last published guidelines on 2012 for the management of thyroid dysfunction during pregnancy and postpartum, "Universal screening of healthy women for thyroid dysfunction before pregnancy is not recommended" and "The committee could not reach agreement with regard to screening recommendations for all newly pregnant women." Increased knowledge about the interaction between the thyroid and pregnancy has changed our view about the definition and diagnosis of thyroid dysfunction in pregnancy (15-18); for example, we have recently found that thyroid stimulating hormone (TSH) level of $2.5 \mathrm{mIU} / \mathrm{L}$ in the first trimester has been accepted as the upper limit of normal range (15). This fact has an important implication in interpretation of the previous literature as well as a critical effect on diagnosis of clinical hypothyroidism.

Copyright (C) 2014, Research Institute For Endocrine Sciences and Iran Endocrine Society; Published by Kowsar. This is an open-access article distributed under the terms of the Creative Commons Attribution-NonCommercial 4.0 International License (http://creativecommons.org/licenses/by-nc/4.0/) which permits copy and redistribute the material just in noncommercial usages, provided the original work is properly cited. 
Saki F et al.

Considering these changes, the American thyroid association has published a new guideline in 2011 for an accurate diagnosis and management of thyroid disease in pregnancy. This guideline determined the normal limits of TSH in the second trimester as 0.2 to $3 \mathrm{mIU} / \mathrm{L}$ and free thyroxin (FT4) as 12 to $30 \mathrm{pmol} / \mathrm{L}$ (15). Subsequent to these changes in definition of thyroid diseases in pregnancy, it is necessary to reevaluate the accurate prevalence of thyroid diseases in pregnancy and their mentioned effects in previous studies (1-3, 12-14).

\section{Objectives}

Recent changes in definition of thyroid diseases in pregnancy has resulted in changes in interpretation of previous studies about the prevalence and effect of thyroid diseases on pregnancy outcomes after 2011. In addition, due to lack of sufficient data about the prevalence and pregnancy outcomes of thyroid disease in Iran, this prospective study aimed to evaluate the prevalence of thyroid diseases and its outcomes in pregnancy in Fars Province, south of Iran.

\section{Material and Methods}

\subsection{Studied Population}

This prospective study included 600 singleton pregnant women who were in consecutive follow-up at Shiraz University of Medical Sciences obstetric hospitals (Zeinabieh Hospital and Hafez Hospital), Shiraz, Iran. Shiraz is the capital city of Fars Province in the south of Iran. In 2000, Iran was considered as an iodine sufficient country by the World Health Organization and in previous reports, Iranian pregnant women were also Iodine sufficient (19, 20). This study was conducted from June 2011 to March 2012. Informed consent was obtained from each patient included in the study and the study protocol conforms to the ethical guidelines of the 1975 Declaration of Helsinki as reflected in a priori approval by the Shiraz University of Medical Sciences' Human Research Committee. Inclusion criteria were healthy singleton pregnancy, residents in Fars Province, and pregnancy with gestational age of 15 to 28 weeks. In the first visit, individuals at high risk for thyroid illness according to their medical history, physical examination, or prior biochemical information had been considered and the women were excluded if they had known chronic diseases such as thyroid diseases, usage of thyroid drugs, diabetes mellitus, and hypertension. Data about maternal age, parity, obstetric history, gestational age (determined by last menstrual period), medical history of thyroid drug usage, and physical examination of the mother were collected twice: in the second trimester of pregnancy and at delivery. Physical examination of the neonate was done in delivery room to determine Apgar score, resuscitation at birth, weight, Head circumference, and length in the hospital.

\subsection{Definition of Complications}

preeclampsia was diagnosed when a pregnant woman develops both of the followings:1) systolic blood pressure $>140 \mathrm{~mm} \mathrm{Hg}$ and/or diastolic blood pressure $>90 \mathrm{~mm}$ $\mathrm{Hg}$ at two separate visits with at least six hour interval in a previously normotensive woman; and 2) proteinuria $\geq$ $0.3 \mathrm{~g} / 24$ hours (21). IUGR was defined as birth weight $\leq$ 10 th percentile for its gestational age $(22,23)$. Preterm delivery was defined as the delivery before the end of 37th week of gestational age (24). Apgar score was determined by evaluating the newborn on five simple criteria on a scale from zero to two and summing up the five values. The resulting Apgar score ranges from zero to ten. The five criteria are appearance, pulse, grimace, activity, and respiration. The first minute Apgar score $<7$ was defined as low Apgar score (25).

\subsection{Thyroid Function Tests}

For thyroid function tests (TFT), 10-mL blood sample of pregnant women was drawn at the first visit in the second trimester; then it was centrifuged and stored in aliquots at $-70^{\circ} \mathrm{C}$ until assays, which were done after delivery. TFT were assessed by quantitative analysis of serum TSH and FT4 (Electrochemiluminescence, CobasE411, Japan). The inter-assay and intra-assay coefficients of variation were respectively $<8.6 \%$ and $<8.7 \%$ for TSH; in addition, these values were $<2.9 \%$ and $<6.6 \%$ for FT4, respectively. TSH was mentioned as $\mathrm{mIU} / \mathrm{L}$ and FT4 as pmol/L.

\subsection{Categorizing Thyroid Function Tests}

According the last guideline of American Thyroid Association (ATA) for the diagnosis and management of thyroid disease during pregnancy and postpartum (15), the reference range for the second trimester TSH and FT4 was 0.2 to $3 \mathrm{mIU} / \mathrm{L}$ and $11.84 \pm 3.86 \mathrm{pmol} / \mathrm{L}$, respectively. Considering this recommendation and according to ATA guideline (15), we categorized pregnant women into five groups:

Category 1 (clinical hypothyroidism) was defined as an elevated TSH ( $>3 \mathrm{mIU} / \mathrm{L})$ in conjunction with a low FT4. In Women with TSH $\geq 10 \mathrm{mIU} / \mathrm{L}$, irrespective of their FT4 level, were also considered as clinical hypothyroidism.

Category 2 (subclinical hypothyroidism) was defined if serum TSH was between 3 to $10 \mathrm{mIU} / \mathrm{L}$ with a normal FT4 concentration.

Category 3 (Normal), was those with TSH of 0.2 to 3 mIU/L and FT 4 of $11.84 \pm 3.86$ to.

Category 4 (Subclinical hyperthyroidism) was defined as suppressed TSH (range, 0.1-0.2 mIU/L) with normal FT4.

Category 5 (Overt hyperthyroidism) was defined as any suppressed TSH $(<0.2 \mathrm{mIU} / \mathrm{L})$ when accompanied by high FT4 and anyone with TSH $<0.1 \mathrm{mIU} / \mathrm{L}$ irrespective of FT4 level. In addition, we calculated the prevalence of isolated hypothyroxinemia according to ATA guideline in which TSH was in normal range but had low FT4. 
Saki F et al.

\subsection{Statistical Analysis}

Analysis was done using SPSS 18 (SPSS Inc., Chicago, IL, USA). Normality of the quantitative variables was assessed by Kolmogorov-Simonov test. To compare difference across groups, ANOVA was used for normally distributed variables and Kruskal-Wallis test was used in those without normal distribution. Data were mentioned as mean \pm SD or median. For serum TSH, free triiodothyronine (FT3), and FT4, 2.5th, 25th, 50th, 75th, and 97.5th percentiles were calculated by frequency analysis. Then the information about TFT was classified in five categories according to ATA guideline. As previously mentioned, category 3 was normal thyroid function pregnant women and was used as control group. The influence of thyroid diseases was analyzed by comparing the frequencies of each outcome in the abovementioned categories. Proportional data were compared using logistic regression analysis. This analysis was adjusted for the confounding factors. Results of analysis were mentioned as relative risk (RR) and the corresponding 95\% confidence interval (95\% CI). P value $<0.05$ was considered as statistically significant.

\section{Results}

Out of 600 enrolled women in our study, 14 refused to follow the study. Ultimately, 586 women participated in our investigation to the end. The mean of participants age was $25.6 \pm 3.6$ years, mean of their weight was $63.4 \pm$ $9.1 \mathrm{~kg}$, and the mean of their height was $162.5 \pm 6.7 \mathrm{~cm}$. Fourteen women (2.4\%) had clinical hypothyroidism, 66 (11.3\%) had subclinical hypothyroidism, 2 (0.3\%) had subclinical hyperthyroidism, and 7 (1.2\%) had overt hyperthyroidism. isolated hypothyroxinemia was diagnosed in $1.4 \%$ of patients. General characteristics of the mothers (height, weight, and age) in each category are summarized in Table 1. Only one mother was cigarette smoker. There was no significant difference in general characteristics of mothers in different thyroid function categories $(\mathrm{P}>0.05)$. The mean of gestational age at delivery was $38 \pm$ 1.9 weeks. The mean of the newborns head circumference was $35.4 \pm 1.7 \mathrm{~cm}$, mean of their weight was $2599 \pm 385 \mathrm{~g}$, and mean of their length was $50.9 \pm 2.8 \mathrm{~cm}$. The neonates had an Apgar score of $8.4 \pm 1.1$ at first minute of delivery. General characteristics of the neonates are categorized according to maternal thyroid function in Table 2.

\begin{tabular}{|c|c|c|c|c|c|c|c|}
\hline Category & I & II & III & IV & $\mathbf{V}$ & Pvalue & Total \\
\hline Frequency, No. (\%) & $14(2.4)$ & $66(11.3)$ & $497(84.8)$ & $2(0.3)$ & $7(1.2)$ & & $586(100)$ \\
\hline Age, $y$ & $27 \pm 4$ & $25.8 \pm 3.5$ & $25.5 \pm 3.6$ & $24.4 \pm 2.1$ & $26.3 \pm 2.9$ & 0.543 & $25.6 \pm 3.6$ \\
\hline Weight, $\mathbf{k g}^{\mathrm{e}}$ & $65.1 \pm 11.6$ & $61.9 \pm 9$ & $63.6 \pm 9$ & $74 \pm 1.4$ & $59.4 \pm 3.1$ & 0.11 & $63.4 \pm 9.1$ \\
\hline Height, cm & $161.7 \pm 4.5$ & $162.6 \pm 3.3$ & $162.5 \pm 7.2$ & $166.5 \pm 0.7$ & $161 \pm 4.4$ & 0.102 & $162.5 \pm 6.7$ \\
\hline BMI, $\mathrm{kg} / \mathrm{m}^{2}$ & $24.8 \pm 3.4$ & $23.4 \pm 2.9$ & $29.3 \pm 1.18$ & $26.7 \pm 0.73$ & $22.9 \pm 1.4$ & 0.140 & $17.4 \pm 3.2$ \\
\hline sBP, mm Hg & $115.3 \pm 21.3$ & $110.9 \pm 20.6$ & $110.4 \pm 15$ & $100 \pm 0.1$ & $107.8 \pm 8.1$ & 0.243 & $105.44 \pm 18.15$ \\
\hline dBP, $\mathrm{mm} \mathrm{Hg}$ & $78.6 \pm 11.3$ & $76.9 \pm 10.1$ & $76.3 \pm 10.5$ & $70 \pm 7.07$ & $77.2 \pm 7.6$ & 0.769 & $74.07 \pm 11.03$ \\
\hline Gestation at Delivery, wk & $38.1 \pm 3.1$ & $37.8 \pm 1.9$ & $38.1 \pm 1.9$ & $38.6 \pm 0.71$ & $38.3 \pm 1.5$ & 0.747 & $38 \pm 1.9$ \\
\hline Cigarette Smoker & 0 & 1 & 0 & 0 & 0 & & $1(0.2)$ \\
\hline Mode of Delivery, Number of CS & $2(14.3)$ & $12(18.2)$ & $81(16.3)$ & $0(0)$ & $0(0)$ & 0.513 & $95(16.2)$ \\
\hline
\end{tabular}

a Categories are defined as follows: I, Clinical hypothyroidism; II, subclinical hypothyroidism; III, euthyroid (control); IV, subclinical hyperthyroidism; V, over hypothyroidism.

b Data are presented as mean \pm SD or No. (\%.)

C $\mathrm{P}$ Value across groups according to the diagnosis of thyroid functions (category I-V).

d Abbreviations: BMI, body mass index; sBP, systolic blood pressure; dBP, diastolic blood pressure; CS, Cesarean section delivery.

e Weight was measured in 14 th week of gestation.

Table 2. General Characteristics of the Newborns at Delivery With Respect to Maternal Thyroid Function Tests a,b,c

\begin{tabular}{|c|c|c|c|c|c|c|c|}
\hline Category & I & II & III & IV & V & Total & PValue \\
\hline Frequency & $14(2.4)$ & $66(11.3)$ & $497(84.8)$ & $2(0.3)$ & $7(1.2)$ & $586(100)$ & - \\
\hline $\begin{array}{l}\text { Gestational Age, } \\
\text { wk }\end{array}$ & $38.1 \pm 3.1(38.8)$ & $37.8 \pm 1.9(38.3)$ & $38 \pm 1.9(38.4)$ & $38.6 \pm 0.7(38.6)$ & $38.3 \pm 1.4(38.4)$ & $38 \pm 1.9(38.3)$ & 0.747 \\
\hline $\begin{array}{l}\text { Head Circumfer- } \\
\text { ence, } \mathrm{cm}\end{array}$ & $35.2 \pm 1.1(35.3)$ & $35.4 \pm 1.4(35.8)$ & $35.4 \pm 1.8(35.8)$ & $36 \pm 0.4(36)$ & $34.8 \pm 1.1(35.3)$ & $35.4 \pm 1.7(35.7)$ & 0.25 \\
\hline Weight, g & $2677 \pm 428(2740$ & $2563 \pm 468(2610)$ & $2603 \pm 372(2640)$ & $2550 \pm 70(2550)$ & $2502 \pm 466(2400)$ & $2599 \pm 385(2635)$ & 0.763 \\
\hline Length, cm & $51.1 \pm 3.3(51)$ & $50.6 \pm 3.3(51.3)$ & $50.9 \pm 2.7(51)$ & $51 \pm 2.8(51)$ & $51.7 \pm 3.3(52)$ & $50.9 \pm 2.8(51)$ & 0.102 \\
\hline $\begin{array}{l}\text { Apgar Score, 1st } \\
\text { Minute }\end{array}$ & $8.5 \pm 1.3(9)$ & $8.2 \pm 1.4(9)$ & $8.4 \pm 1.1(9)$ & $10 \pm 0(10)$ & $8.1 \pm 1.2(9)$ & $8.4 \pm 1.1(9)$ & 0.125 \\
\hline
\end{tabular}

\footnotetext{
${ }^{a}$ Categories are defined as follows: I, Clinical hypothyroidism; II, Subclinical hypothyroidism; III, Euthyroid (control); IV, Subclinical hyperthyroidism; V, over hypothyroidism.

$\mathrm{b}$ Data are presented as mean \pm SD or No. (\%.).

C P Value across groups according to the diagnosis of thyroid functions (category I-V).
} 
Saki F et al.

There was no significant difference between gestational age, head circumference, weight, length, and Apgar score of neonates in different thyroid function categories ( $\mathrm{P}>$ 0.05). Distribution of serum TSH had a non-Gaussian distribution. After logarithmic transformation (log and $\ln$ ), normality was not achieved. Therefore, the rank numbers of 2.5th to 97.5th percentiles were used to estimate the lower and the upper limits of the reference interval, respectively. 2.5th, 25th, 50th, 75th, and 97.5th percentiles for FT3 and FT4, which had normal distribution, were calculated by frequency analysis. These percentiles were calculated for TSH, FT3, and FT4. All data are summarized in Table 3. Median (interquartile range) for subclinical hypothyroidism and overt hypothyroidism was 3.65 (3.18 4.93) and 12.1 (4.42-15.22), respectively.

Table 3. Percentile Values for Thyroid Function Test of the Pregnant Women in the Second Trimester of Pregnancy ${ }^{a, b}$

\begin{tabular}{lcccccc}
\hline Thyroid Function Tests & \multicolumn{5}{c}{ Observed Percentiles } \\
\cline { 2 - 6 } & 2.5th & 25th & 50th & 75th & 97.5th \\
\hline TSH, mIU/L & 0.51 & 1.18 & 1.68 & 2.4 & 4.9 \\
FT3, pmol/L & 8 & 11.1 & 12.8 & 14.5 & 17.7 \\
FT4, pmol/L & 7.85 & 10.68 & 12.36 & 14.29 & 17.89 \\
\hline $\begin{array}{l}\text { a Data of 586 pregnant women. } \\
\text { b Abbreviations: TSH, thyroid }\end{array}$ & stimulating & hormone, FT3, free \\
triiodothyronine; and FT4, free thyroxine. & & & &
\end{tabular}

\subsection{Pregnancy outcomes}

Prevalence rates of preeclampsia, IUGR, preterm delivery and low Apgar score in participants were 6.3\%, $7.5 \%, 14.5 \%$, and $8 \%$, respectively. Rout of delivery in $16.2 \%$ of mothers was cesarean section. In women with hypo- thyroidism, prevalence rate of preeclampsia, IUGR, preterm delivery, and low Apgar score was 7.5\%, 13.7\%, 21.2\%, and $13.7 \%$, respectively. Prevalence rates of preeclampsia, IUGR, preterm delivery and low Apgar score in women with hyperthyroidism were $0 \%, 22.2 \%, 11.1 \%$, and $11.1 \%$, respectively. All data are summarized in Table 4.

\subsection{Hypothyroidism and Pregnancy Outcomes}

Prevalence of hypothyroidism in pregnant woman was 13.7\% (clinical, 2.4\%; and subclinical, 11.3\%). Hypothyroidism was associated with IUGR $(\mathrm{P}=0.017)$ and low Apgar score at first minute $(\mathrm{P}=0.04)$; it increased the risk of IUGR by 2.2 times and low Apgar score by 1.95 times. Clinical hypothyroidism had no significant association with preeclampsia $(\mathrm{P}>0.05)$, but was associated with preterm delivery $(\mathrm{P}=0.045)$. Subclinical hypothyroidism had a significant association with IUGR $(P=0.028)$ and low Apgar score at first minute $(\mathrm{P}=0.022)$. It increased the risk of low Apgar score by 2.15 times and IUGR by 2.18 times. This regression analysis for IUGR was adjusted for maternal body mass index (BMI), age of mother, and occurrence of preeclampsia. Moreover, logistic regression analysis for neonates with low Apgar score was adjusted for delivery gestational age, maternal BMI, age of mother, and occurrence of preeclampsia. The adjustment for preterm delivery included maternal age, maternal BMI, and preeclampsia. The analysis adjustment for preeclampsia included age of mother and maternal BMI. After this adjustment, no significant change in associations was found, except for the preterm delivery. The association of clinical hypothyroidism and preterm delivery was not significant $(P$ value $=0.116)$ after adjustment for confounding factors. All data are summarized in Table 4.

\begin{tabular}{|c|c|c|c|c|}
\hline Mothers' Thyroid status & Preeclampsia & IUGR & Preterm Delivery & Low Apgar Score \\
\hline Euthyroid $(n=497)$ & $31(6)$ & $31(6)$ & $67(13)$ & $35(7)$ \\
\hline \multicolumn{5}{|c|}{ Clinical Hypothyroidism $(n=14)$} \\
\hline Frequency, No (\%) & $2(14)$ & $2(14)$ & $5(36)$ & $1(7)$ \\
\hline $\mathrm{RR}(95 \% \mathrm{CI})$ & $2.29(0.6-8.64)$ & $2.28(0.6-8.6)$ & $2.12(0.9-5)$ & $1.01(0.15-6.89)$ \\
\hline Pvalue & 0.227 & 0.228 & $0.045^{\mathrm{c}}$ & 0.988 \\
\hline \multicolumn{5}{|c|}{ Subclinical Hypothyroidism $(\mathrm{n}=66)$} \\
\hline Frequency, No. (\%) & $4(6.1)$ & $9(13.6)$ & $12(18.3)$ & $10(15.2)$ \\
\hline $\mathrm{RR}(95 \% \mathrm{CI})$ & $0.97(0.35-2.66)$ & $2.18(1.08-4.37)$ & $1.35(0.77-2.35)$ & $2.15(1.12-4.14)$ \\
\hline Pvalue & 0.955 & 0.028 & 0.302 & 0.022 \\
\hline \multicolumn{5}{|c|}{ Total Mothers With Hypothyroidism $(\mathbf{n}=\mathbf{8 0})$} \\
\hline Frequency, No (\%) & $6(75)$ & $11(13.7)$ & $17(21.2)$ & $11(13.7)$ \\
\hline $\mathrm{RR}(95 \% \mathrm{CI})$ & $1.2(0.52-2.8)$ & $2.2(1.15-4.2)$ & $1.48(0.9-2.4)$ & $1.95(1.03-3.68)$ \\
\hline Pvalue & 0.67 & 0.017 & 0.12 & 0.04 \\
\hline
\end{tabular}

\footnotetext{
${ }^{a}$ Abbreviations: IUGR, intrauterine growth restriction; RR, relative risk; CI, confidence interval.

${ }^{\mathrm{b}} \mathrm{P}$ values are the result of Chi square analysis of the frequency of each complication between abnormal thyroid function mothers and euthyroid ones (as controls).

${ }^{\mathrm{C}}$ No significant change in associations was seen after adjusting the analysis for the confounding factors except for the P value of the analysis of clinical hypothyroidism and preterm delivery, which was change to 0.116 after adjusting this analysis for maternal BMI, age, and preeclampsia.
} 
Saki F et al.

\begin{tabular}{|c|c|c|c|c|}
\hline Mothers' Thyroid Status & Preeclampsia & IUGR & Preterm Delivery & Low Apgar Score \\
\hline Euthyroid $(n=497)$ & $31(6)$ & $31(6)$ & $67(13)$ & $35(7)$ \\
\hline \multicolumn{5}{|c|}{ Clinical Hyperthyroidism $(\mathbf{n}=7)$} \\
\hline Frequency, No. (\%) & $0(0)$ & $2(28)$ & $1(14)$ & $1(14)$ \\
\hline $\mathrm{RR}(95 \% \mathrm{CI})$ & - & $4.57(1.35-15.48)$ & $1.06(0.17-6.5)$ & $2.03(0.32-12.8)$ \\
\hline P Value & - & 0.018 & 0.951 & 0.460 \\
\hline \multicolumn{5}{|c|}{ Subclinical Hyperthyroidism $(\mathrm{n}=2)$} \\
\hline Frequency, No (\%) & 0 & 0 & 0 & 0 \\
\hline $\mathrm{RR}(95 \% \mathrm{CI})$ & - & - & - & - \\
\hline PValue & - & - & - & - \\
\hline \multicolumn{5}{|c|}{ Total Mothers With Hyperthyroidism $(\mathbf{n}=9)$} \\
\hline Frequency, No (\%) & $0(0)$ & $2(22.2)$ & $1(11.1)$ & $1(11.1)$ \\
\hline $\mathrm{RR}(95 \% \mathrm{CI})$ & - & $3.5(1-12.64)$ & $0.82(0.128-5.3)$ & $1.58(0.24-10.29)$ \\
\hline P Value & - & 0.048 & 0.84 & 0.638 \\
\hline
\end{tabular}

\subsection{Hyperthyroidism and Pregnancy Outcomes}

Prevalence of hyperthyroidism in pregnant women was $1.5 \%$ (overt, $1.2 \%$; and subclinical, $0.3 \%$ ). Maternal hyperthyroidism was associated with IUGR $(P=0.048)$. It increased the risk of IUGR by 4.57 times. Nevertheless, it did not show a significant association with preeclampsia, preterm delivery, and low Apgar score. Only two mothers presented with subclinical hyperthyroidism and had no complication. Overt hyperthyroidism was associated with IUGR $(P=0.018)$. These results for each complication were not significantly changed in logistic regression analysis after covariates were adjusted for abovementioned confounding factors. All data are summarized in Table 5.

\section{Discussion}

We have investigated the normal distribution of TSH in our 586 pregnant women and showed that our range for the level of TSH in Iran was higher than the ATA ranges (15). Our data were similar to those of previous reported from India and Iran in which the ranges of TSH in the second trimester were about 0.43 to 5.78 and 0.5 to $4.1 \mathrm{mIU} / \mathrm{L}$, respectively (26-28). Differences in laboratory methods, differences in kits, maternal iodine status, and ethnic, genetic, and environmental factors in our and other similar studies could explain these differences. On the other hand, other studies report a lower range for TSH level (2933). After publishing the ATA guideline, we have found some studies in which the thyroid function status was evaluated according to this guideline $(3,7,21)$. The present study provides, for the first time, the data about the thyroid function status in Iranian pregnant women ac- cording to this new guideline. We found that prevalence of hypothyroidism in pregnancy was $13.7 \%$ (clinical, $2.4 \%$; and subclinical, $11.3 \%$ ). In addition, $1.4 \%$ of our pregnant women had isolated hypothyroxinemia. According to previous reports, prevalence of clinical hypothyroidism in pregnant women ranged from $1 \%$ to $3.5 \%$ and subclinical hypothyroidism ranged from $4 \%$ to $31 \%(1-8,22)$. Prevalence of hyperthyroidism of pregnant women was $1.5 \%$ in our study (subclinical, 0.3\%; and over, 1.2\%). In previous reports, prevalence of hyperthyroidism was reported as $0.2 \%$ to $2 \%(1-8,22)$. One of the causes of variation in prevalence of thyroid dysfunction might be variation in definition of normal range for TSH in different studies. The ATA recommendations could orchestrate the investigations about the prevalence and effects of thyroid dysfunction and prevent the errors in our interpretations and clinical judgment about the detrimental effects of thyroid dysfunction on pregnancy outcomes. Hypertension is one of the most important health problems related to both overt hypothyroidism and hyperthyroidism $(1,34)$ and to a lesser extent, to subclinical thyroid dysfunction (35). The prevalence of preeclampsia was $6.3 \%$ in our pregnant women. Its prevalence was $6 \%, 7.5 \%$, and $0 \%$ in euthyroid mothers, mothers with hypothyroidism, and mothers with hyperthyroidism, respectively. Although the prevalence of preeclampsia was higher in pregnant women with hypothyroidism, this difference was not statistically significant. A few investigations have reported that overt hypothyroidism increases the incidence of preeclampsia $(8,9)$; however most of the studies showed no significant association $(1,3,7)$. Prevalence of preterm delivery was $13 \%, 21 \%$, and $11.1 \%$ in euthyroid mothers, mothers with hypothyroidism, and mothers with hyperthyroidism, 
respectively. We have found that thyroid dysfunction did not associate with preterm delivery. Spontaneous abortion and preterm delivery have been reported in $17 \%$ to $31 \%$ of all pregnancies $(36,37)$. The majority of them have no known risk factor (6). One of the known risk factors is clinical or subclinical hypothyroidism (38-40). Allan et al. showed that TSH level $>6 \mathrm{mIU} / \mathrm{L}$ was significantly associated with a higher frequency of pregnancy loss (39); however, one recent study showed no significant associations between TSH level and the risk of preterm delivery (41). We showed that the association of clinical hypothyroidism and preterm delivery might be due to secondary confounding factors such as maternal BMI, age, and preeclampsia. Our study showed that both hyperthyroidism and hypothyroidism are associated with IUGR. A subclinical hypothyroidism of mother increases the risk of IUGR by 2.18 times. Overt hyperthyroidism increases the risk of IUGR for about 4.57 times. Consistent with our results, previous reports revealed that subclinical hypothyroidism was associated with $\operatorname{IUGR}(5,8,42)$. It might be due to the essential role of thyroid hormones in growth and maturation of many tissues of the fetus like the brain, bones, and muscles (43). We revealed that hypothyroidism is associated with low Apgar score and mothers with subclinical hypothyroid have 2.15 times greater risk for having low Apgar score neonates. Consistent with our results, Goel et al. showed a higher risk of fetal distress in mothers with subclinical or clinical hypothyroidism (44). It seems that hypothyroidism exerts irreversible influences on the placenta and fetus during pregnancy and decreases the fetal ability to tolerate stress and therefore, neonates present with low Apgar scores at birth (45). Thyroid peroxidase antibody was not evaluated, which was a limitation to our study. Therefore, future studies should evaluate thyroid autoantibodies in addition to TFT. In our study, we found that the hypothyroidism during pregnancy, even in subclinical form, could cause IUGR and low Apgar score. Although prevalence of hyperthyroidism in our pregnant women was very low, it could be associated with IUGR. Interventional studies are required to determine whether early diagnosis and treatment of thyroid diseases, even in the subclinical form, prevent their adverse effect on the fetus in Iranian pregnant women.

\section{Acknowledgements}

The authors would like to thank Dr. Nasrin Shokrpour for editorial assistance and Mrs Sareh Roosta for statistical analysis at Center for Development of Clinical Research of Nemazee Hospital.

\section{Author's Contributions}

Study concept and Design: Dr. Dabbaghmanesh, Ms. Ghaemi, Mrs. Foroohari, and Dr. Bakhshayeshkaram; analysis and interpretation of data: Dr. Saki, Dr. Dabbaghmanesh; drafting of the manuscript: Dr. Saki, Dr. Dabbaghmanesh; Critical revision of the manuscript for important intellectual content: Dr Omrani, and Dr Dabbaghmanesh; and Statistical analysis: Dr. Saki and Dr. Dabbaghmanesh.

\section{Funding Support}

Shiraz University of Medical Sciences financially supported the study.

\section{References}

1. Mannisto T, Vaarasmaki M, Pouta A, Hartikainen AL, Ruokonen A, Surcel HM, et al. Thyroid dysfunction and autoantibodies during pregnancy as predictive factors of pregnancy complications and maternal morbidity in later life.J Clin Endocrinol Metab. 2010;95(3):1084-94.

2. Glinoer D. The regulation of thyroid function in pregnancy: pathways of endocrine adaptation from physiology to pathology. Endocr Rev. 1997;18(3):404-33

3. Karakosta P, Alegakis D, Georgiou V, Roumeliotaki T, Fthenou E, Vassilaki M, et al. Thyroid dysfunction and autoantibodies in early pregnancy are associated with increased risk of gestational diabetes and adverse birth outcomes. J Clin Endocrinol Metab. 2012;97(12):4464-72.

4. Skjoldebrand L, Brundin J, Carlstrom A, Pettersson T. Thyroid associated components in serum during normal pregnancy. Acto Endocrinol (Copenh). 1982;100(4):504-11.

5. Su PY, Huang K, Hao JH, Xu YQ, Yan SQ, Li T, et al. Maternal thyroid function in the first twenty weeks of pregnancy and subsequent fetal and infant development: a prospective population-based cohort study in China. J Clin Endocrinol Metab. 2011;96(10):323441.

6. Stagnaro-Green A. Maternal thyroid disease and preterm delivery. J Clin Endocrinol Metab. 2009;94(1):21-5.

7. Mannisto T, Mendola P, ReddyU, Laughon SK. Neonatal outcomes and birth weight in pregnancies complicated by maternal thyroid disease. Am J Epidemiol. 2013;178(5):731-40.

8. Sahu MT, Das V, Mittal S, Agarwal A, Sahu M. Overt and subclinical thyroid dysfunction among Indian pregnant women and its effect on maternal and fetal outcome. Arch Gynecol Obstet. 2010;281(2):215-20

9. Poppe K, Glinoer D. Thyroid autoimmunity and hypothyroidism before and during pregnancy. Hum Reprod Update. 2003;9(2):14961.

10. Vanderpump MP, Tunbridge WM. Epidemiology and prevention of clinical and subclinical hypothyroidism. Thyroid. 2002;12(10):839-47.

11. Mestman JH, Goodwin TM, Montoro MM. Thyroid disorders of pregnancy. Endocrinol Metab Clin North Am.1995;24(1):41-71.

12. Leung AS, Millar LK, Koonings PP, Montoro M, Mestman JH. Perinatal outcome in hypothyroid pregnancies. Obstet Gynecol. 1993;81(3):349-53.

13. Mestman JH. Hyperthyroidism in pregnancy. Endocrinol Metab Clin North Am.1998;27(1):127-49.

14. Millar LK, Wing DA, Leung AS, Koonings PP, Montoro MN, Mestman JH. Low birth weight and preeclampsia in pregnancies complicated by hyperthyroidism. Obstet Gynecol.1994;84(6):946-9.

15. Stagnaro-Green A, Abalovich M, Alexander E, Azizi F, Mestman J, Negro R, et al. Guidelines of the American Thyroid Association for the diagnosis and management of thyroid disease during pregnancy and postpartum. Thyroid. 2011;21(10):1081-125.

16. Abalovich M, Amino N, Barbour LA, Cobin RH, De Groot LJ, Glinoer D, et al. Management of thyroid dysfunction during pregnancy and postpartum: an Endocrine Society Clinical Practice Guideline. J Clin Endocrinol Metab. 2007;92(8 Suppl):S1-47.

17. Gharib H, Cobin RH, Dickey RA. Subclinical hypothyroidism during pregnancy: position statement from the American Association of Clinical Endocrinologists. Endocr Pract.1999;5(6):367-8.

18. Kahric-Janicic N, Soldin SJ, Soldin OP, West T, Gu J, Jonklaas J. Tan dem mass spectrometry improves the accuracy of free thyroxine measurements during pregnancy. Thyroid. 2007;17(4):303-11. 
19. Azizi F, Hosseini MS, Amouzegar A, Tohidi M, Ainy E. Neonatal thyroid status in an area of iodine sufficiency.J Endocrinol Invest. 2011;34(3):197-200.

20. Azizi F, Mehran L. Experiences in the prevention, control and elimination of iodine deficiency disorders: a regional perspective. East Mediterr Health J. 2004;10(6):761-70.

21. Sibai BM. Diagnosis and management of gestational hypertension and preeclampsia. Obstet Gynecol. 2003;102(1):181-92.

22. Gardosi J. New definition of small for gestational age based on fetal growth potential. Horm Res. 2006;65 Suppl 3:15-8.

23. Kramer MS. Determinants of low birth weight: methodological assessment and meta-analysis. Bull World Health Organ. 1987;65(5):663-737.

24. Goldenberg RL, Culhane JF, Iams JD, Romero R. Epidemiology and causes of preterm birth. Lancet. 2008;371(9606):75-84

25. Finster M, Wood M. The Apgar score has survived the test of time. Anesthesiology. 2005;102(4):855-7.

26. Mehran L, Amouzegar A, Delshad H, Askari S, Hedayati M Amirshekari G, et al. Trimester-specific reference ranges for thyroid hormones in Iranian pregnant women. J Thyroid Res. 2013;2013:651517.

27. Marwaha RK, Chopra S, Gopalakrishnan S, Sharma B, Kanwar RS, Sastry A, et al. Establishment of reference range for thyroid hormones in normal pregnant Indian women. BJOG. 2008;115(5):602-6.

28. Azizi F, Mehran L, Amouzegar A, Delshad H, Tohidi M, Askari S, et al. Establishment of the trimester-specific reference range for free thyroxine index. Thyroid. 2013;23(3):354-9.

29. Haddow JE, Knight GJ, Palomaki GE, McClain MR, Pulkkinen AJ. The reference range and within-person variability of thyroid stimulating hormone during the first and second trimesters of pregnancy. J Med Screen. 2004;11(4):170-4.

30. Stricker R, Echenard M, Eberhart R, Chevailler MC, Perez V, Quinn FA, et al. Evaluation of maternal thyroid function during pregnancy: the importance of using gestational age-specific reference intervals. Eur JEndocrinol. 2007;157(4):509-14.

31. Panesar NS, Li CY, Rogers MS. Reference intervals for thyroid hormones in pregnant Chinese women. Ann Clin Biochem. 2001;38(Pt 4):329-32.

32. Soldin OP, Soldin D, Sastoque M. Gestation-specific thyroxine and thyroid stimulating hormone levels in the United States and worldwide. Ther Drug Monit. 2007;29(5):553-9.

33. Korevaar TI, Medici M, de Rijke YB, Visser W, de Muinck KeizerSchrama SM, Jaddoe VW, et al. Ethnic differences in maternal thy- roid parameters during pregnancy: the Generation R study.J Clin Endocrinol Metab. 2013;98(9):3678-86.

34. Fazio S, Palmieri EA, Lombardi G, Biondi B. Effects of thyroid hormone on the cardiovascular system. Recent Prog Horm Res. 2004;59:31-50.

35. Walsh JP, Bremner AP, Bulsara MK, O'Leary P, Leedman PJ, Feddema $\mathrm{P}$, et al. Subclinical thyroid dysfunction and blood pressure: a community-based study. Clin Endocrinol (Oxf). 2006;65(4):486-91.

36. Ellish NJ, Saboda K, O'Connor J, Nasca PC, Stanek EJ, Boyle C. A prospective study of early pregnancy loss. Hum Reprod. 1996;11(2):406-12.

37. Wilcox AJ, Weinberg CR, O'Connor JF, Baird DD, Schlatterer JP, Canfield RE, et al. Incidence of early loss of pregnancy. $N$ Engl J Med.1988;319(4):189-94.

38. Abalovich M, Gutierrez S, Alcaraz G, Maccallini G, Garcia A, Levalle O. Overt and subclinical hypothyroidism complicating pregnancy. Thyroid. 2002;12(1):63-8.

39. Allan WC, Haddow JE, Palomaki GE, Williams JR, Mitchell ML, Hermos RJ, et al. Maternal thyroid deficiency and pregnancy complications: implications for population screening. J Med Screen. 2000;7(3):127-30.

40. Kilby MD, Verhaeg J, Gittoes N, Somerset DA, Clark PM, Franklyn JA. Circulating thyroid hormone concentrations and placental thyroid hormone receptor expression in normal human pregnancy and pregnancy complicated by intrauterine growth restriction (IUGR). J Clin Endocrinol Metab. 1998;83(8):2964-71.

41. Stagnaro-Green A, Chen X, Bogden JD, Davies TF, Scholl TO. The thyroid and pregnancy: a novel risk factor for very preterm delivery. Thyroid. 2005;15(4):351-7.

42. Casey BM, Dashe JS, Wells CE, McIntire DD, Byrd W, Leveno KJ, et al. Subclinical hypothyroidism and pregnancy outcomes. Obstet Gynecol. 2005;105(2):239-45.

43. Rivkees SA, Bode HH, Crawford JD. Long-term growth in juvenile acquired hypothyroidism: the failure to achieve normal adult stature. N Engl J Med.1988;318(10):599-602.

44. Goel P, Radotra A, Devi K, Malhotra S, Aggarwal A, Huria A. Maternal and perinatal outcome in pregnancy with hypothyroidism. Indian J Med Sci. 2005;59(3):116-7.

45. Mannisto T, Vaarasmaki M, Pouta A, Hartikainen AL, Ruokonen A Surcel HM, et al. Perinatal outcome of children born to mothers with thyroid dysfunction or antibodies: a prospective population-based cohort study.JClin Endocrinol Metab.2009;94(3):772-9. 